\title{
Optimizing coal blending quality through supplier selection and order allocation: A case of cement industry
}

\author{
Dicky Fatrias ${ }^{1 *}$, Nilda Tri Putri ${ }^{1}$, Pri Gustari Akbar ${ }^{2}$, and Fidela Andari Fae ${ }^{1}$ \\ ${ }^{1}$ Dept. Of Industrial Engineering, Andalas University, 25163 Padang, Indonesia \\ ${ }^{2}$ Department of Purchasing, Semen Padang Co., 25237 Padang, Indonesia
}

\begin{abstract}
Coal combustion plays an important role in the process of burning raw mix into cement clinker. However, ensuring a uniform coal quality is quite challenging especially when cement producer adopts multisourcing system where different suppliers involved to supply coal demand. This research explores the optimal coal blending quality problem in SP Co., as one of the largest cement industry in Indonesia, where the coal is supplied from several suppliers characterized by heterogenous and fluctuated coal quality. In detail, the problem is to select a set of suppliers and to determine optimal order allocation of coal for supplying three cement plants distinguished by certain requirement of coal specification under some realistic constraints such as quality of coal, allocated budget of purchasing and supplier capacity. A linear programming model is proposed to solve the formulated problem and sensitivity analysis is performed to examined the robustness of the model. Using real case data, we demonstrate the usefulness and applicability of our model.
\end{abstract}

\section{Introduction}

An increasing competition in global market forces enterprise to seek any opportunity to improve efficiency while maintaining high product quality. In particular, the use of energy resource has been highlighted as one of a major source of improvement especially in industries where the use of fuel plays a vital part, not only in gaining a better efficiency, but also in producing product with targeted quality.

SP Co. is one of the largest cement industry in Indonesia where coal is used as primary energy resources. An important process in cement production is clinker production in which raw mix routed from pre-heating process is burned in cement kiln. A stable combustion process should be ensured to produce the specified clinker quality. In this regard, the coal specification plays a vital role to, not only generate ignition, but also produce a stable combustion with targeted burning temperature. Feeding the process with off-specification coal may results in lower burning temperature, thus, lowering quality of clinker. To anticipate this output, more quantity of coal should be added to the combustion process to reach the desired temperature with the expense of additional cost. The company receives

* Corresponding author: dickyf@eng.unand.ac.id 
coal supply from many suppliers of different mining area and region with varying quality. Currently, SP Co. have to use one or more off-specification coals due to transportation problems and economic reasons. The heterogenous and fluctuated coal quality significantly impacts performance of cement kiln and other coal-fired equipment. Therefore, to meet the specified quality and minimize the cost, and realize a reliable and efficient kiln operation, in-house coal blending is planned to be adopted. Blending coals of different quality parameters and price is an appropriate approach to control coal quality to be well within the range specified $[1,2]$.

Several coal blending model has been studied extensively in literatures. Yin et al [3] proposed a novel nonlinear programming (NLP) based neural network for coal blending model of power plants. Liu and Sherali [4] presented a mixed-integer zero-one programming model to find optimal shipping and blending decision of coal pertaining to an electric utility company where the coal is purchased in bulk from overseas. Xi-Jin et al [5] developed a nonlinear model to optimize coal blending parameters used to generate schedule for coal preparation production Plant. Chakraborty [6] proposed multi-objective model to find optimal planning for blending of coal of different grades to satisfy the requirements of the end users with desired specifications. The genetic algorithm is then applied to solve a case study from a regional coal company in India. Vascol et al [7] solved coal blend optimization problem for cokemaking and blast furnace operations by proposing a mixed-integer nonlinear programming (MILP) to determine the minimum cost coal blend composition that satisfies the coke oven pressure and blast furnace stability requirements. This research proposes to find an optimal yet acceptable coal blending quality faced by SP Co. while minimizing total cost of purchasing through selecting supplier and assign order allocation to each of them considering some realistic constraints such as coal quality parameters, coal unit cost and so on. A simple linear programming (LP) model is formulated to ensure easiness and practicality in application. Lastly, sensitivity analysis is performed to examine model elasticity by means of how far the quality paramaters and unit purchasing cost can be deviated in the allowable range of cost.

\section{The Proposed Model}

As stated earlier, SP Co. uses coal as a main fuel to operate cement kiln to produce cement clinker. Coal quality determines the performance of cement kiln in producing a quality clinker. Coal is supplied from many suppliers distinguished by their quality and unit purchasing price. A heterogenous (from one supplier to another) and fluctuated quality (from shipment to another) affects the stability of kiln combustion process. Using offspecification of coal may increase the quantity usage of coal during combustion, thus, increasing cost. There are some quality parameters considered when purchasing coal to suppliers. The parameters includes coal calorific value, total moistures, ash and sulphure. Moreover, there is also main constraint that the average unit purchasing price must not exceed the maximum value set strategically by the top management. Other tecnical constraints include demand and capacity constraints of suppliers. The problem is to find appropritae supplier and order allocation to each supplier to achieve the spesified coal blending quality with minimum total purchasing cost.

\section{Notation:}

$i \quad$ index for supplier, where $i \in I(I=$ set of suppliers $)$

$j \quad$ index for plant, where $j \in J(J=$ set of plant $)$

Parameters:

$D_{j} \quad$ Coal demand of plant $j$ (ton) 
$C_{i} \quad$ Capacity of supplier $i$ (ton)

$B \quad$ Maximum allocated purchasing cost (\$/ton)

$p_{i} \quad$ Unit price of supplier $i$ (\$/ton)

$C V_{i} \quad$ Calorific value of coal from supplier $i(\mathrm{kcal} / \mathrm{kg})$

$T M_{i} \quad$ Percentage of TM content of coal from supplier $i(\%)$

$A_{i} \quad$ Percentage of ash content of coal from supplier $i(\%)$

$S_{i} \quad$ Percentage of sulphur content of coal from supplier $i(\%)$

$m_{j} \quad$ Minimum CV required by plant $j(\mathrm{kcal} / \mathrm{kg})$

$n_{j} \quad$ Maximum percentage of TM content required by plant $j(\%)$

$q_{j} \quad$ Maximum percentage of ash content required by plant $j(\%)$

$r_{j} \quad$ Maximum percentage of sulphur content required by plant $j(\%)$

Decision Variables and Objective Function:

$x_{i j} \quad$ Order allocation from plant $\mathrm{j}$ to supplier $\mathrm{i}$ (ton)

TC Total cost of purchasing (\$)

The LP model is as stated as follow:

Subject to:

$$
T C=\sum_{i=1}^{I} \sum_{j=1}^{J} p_{i j} x_{i j}
$$

$$
\begin{gathered}
\sum_{i=1}^{I} \sum_{j=1}^{J}\left(p_{i}-B\right) x_{i j} \leq 0 \\
\sum_{i=1}^{I} \sum_{j=1}^{J}\left(C V_{i}-m_{j}\right) x_{i j} \geq 0 \\
\sum_{i=1}^{I} \sum_{j=1}^{J}\left(T M_{i}-n_{j}\right) x_{i j} \leq 0 \\
\sum_{i=1}^{I} \sum_{j=1}^{J}\left(A_{i}-q_{j}\right) x_{i j} \leq 0 \\
\sum_{i=1}^{I} \sum_{j=1}^{J}\left(S_{i}-r_{j}\right) x_{i j} \leq 0 \\
\sum_{j=1}^{J} x_{i j} \leq C_{i} \\
\sum_{j=1}^{J} x_{i j}=D_{j} \\
\sum_{i=1}^{I} \sum_{j=1}^{J} x_{i j} \geq 0
\end{gathered}
$$

Eq. (1) is the total cost of purchasing coal to all suppliers. Eq. (2) represents that the average unit purchasing cost of all suppliers must not exceed the maximum unit price allowed set by the company. Eq. (3) - (6) denotes four different quality constraints that should be met by suppliers each of which refers to calorific value (CV), total moisture (TM), ash (A) and sulphur (S). Unlike the CV in (3) which should not less than that of targeted by any plants, the TM, A and S should be greater than the targeted ones, as indicated in (4), (5) and (6), respectively. Eq. (7) ensures that the total order allocation for any particular supplier should be less than supplier capacity. Eq. (8) indicates that all demand should be met. Lastly, non-negativity constraint is added to Eq. (9).

\section{Result and Discussion}

The SP Co. operates three plants each of which produces different types of cement product. The coal quality requirement of each plant and maximum allocated unit purchasing cost are shown in Table 1. At the beginning of each year, SP Co. establish agreement with several coal suppliers to fulfil monthly coal demand during a year long. For 2018, there are 15 suppliers involved, and supplier data and quality characteristic are presented in Table 2. It can be seen that each supplier has different quality characteristic. Based on this characteristics, currently SP Co. categorizes the suppliers into "low", "medium" and "high" 
quality depending on the supplier CV value, which is considered as the main concern for the current purchasing. The low-quality supplier is indicated by their low percentage of ash $(A)$ and sulphur $(S)$ content, possessing larger capacity with lower purchasing price (supplier 1-10). On contrary, the high-quality suppliers are characterized by high calorific value $(C V)$ and total moisture $(T M)$ value but offered expensive price and limited capacity (supplier 12-15). In between, a medium-quality supplier offers intermediate quality with moderate price and capacity (supplier 11).

Table 1. Specification of Quality Parameters

\begin{tabular}{|c|c|c|c|c|c|}
\hline \multirow[b]{2}{*}{ Plant } & \multicolumn{4}{|c|}{ Quality Parameters } & \multirow{2}{*}{$\begin{array}{l}\text { Demand/month } \\
\text { (ton) }\end{array}$} \\
\hline & $\begin{array}{l}\text { Min CV } \\
(\mathrm{kcal} / \mathrm{kg})\end{array}$ & $\begin{array}{c}\text { Max TM } \\
(\%)\end{array}$ & Max A (\%) & $\operatorname{Max} S(\%)$ & \\
\hline $\mathrm{IPa}$ & 5,600 & 35.0 & 15.0 & 1.0 & 109,000 \\
\hline $\mathrm{II} \mathrm{Pa}$ & 5.200 & 40.0 & 15.0 & 1.0 & 5,8000 \\
\hline III $\mathrm{Pa}$ & 6,000 & 20.0 & 15.0 & 1.0 & 3,800 \\
\hline
\end{tabular}

Table 2. Supplier Data and Characteristics

\begin{tabular}{|c|c|c|c|c|c|c|}
\hline \multirow[b]{2}{*}{ Supplier } & \multicolumn{4}{|c|}{ Quality Specification } & \multirow{2}{*}{$\begin{array}{c}\text { Price/ton } \\
\text { (\$) }\end{array}$} & \multirow{2}{*}{$\begin{array}{c}\text { Capacity } \\
\text { (ton/month) }\end{array}$} \\
\hline & $\begin{array}{c}\mathrm{CV} \\
\text { (kcal/kg) }\end{array}$ & TM (\%) & A (\%) & S (\%) & & \\
\hline 1 & 5,300 & 38.0 & 8.0 & 0.5 & 34,81 & 10,000 \\
\hline 2 & 5,300 & 38.0 & 10.0 & 0.5 & 35,56 & 10,000 \\
\hline 3 & 5,500 & 38.0 & 9.0 & 0.7 & 38,52 & 6,000 \\
\hline 4 & 5,500 & 39.0 & 10.0 & 0.5 & 38,52 & 10,000 \\
\hline 5 & 5,500 & 39.0 & 10.0 & 0.5 & 38,89 & 15,000 \\
\hline 6 & 5,400 & 39.0 & 10.0 & 0.5 & 39,26 & 25,000 \\
\hline 7 & 5,500 & 38.0 & 10.0 & 0.5 & 40,74 & 25,000 \\
\hline 8 & 5,600 & 39.0 & 8.0 & 0.5 & 41,11 & 15,000 \\
\hline 9 & 5,600 & 38.0 & 10.0 & 0.5 & 41,48 & 20,000 \\
\hline 10 & 5,500 & 36.0 & 10.0 & 0.4 & 42,22 & 10,000 \\
\hline 11 & 5,800 & 24.0 & 15.0 & 1.0 & 44,44 & 15,000 \\
\hline 12 & 6,764 & 12.0 & 17.0 & 1.0 & 60,00 & 3,000 \\
\hline 13 & 6,800 & 10.0 & 17.0 & 1.0 & 62,96 & 3,000 \\
\hline 14 & 6,800 & 10.0 & 17.0 & 1.0 & 62,96 & 3,000 \\
\hline 15 & 6,800 & 10.0 & 17.0 & 1.0 & 63,70 & 5,000 \\
\hline
\end{tabular}

The proposed model is then applied and the result is shown in Table 3. In general, all suppliers are selected to supply coal demand which results in total cost of $\$ 7,047,259$. Coal demand of Plant 1 is supplied by 12 suppliers from which about $83 \%$ of this supply comes from low-quality supplier ( 8 suppliers), 12\% from medium-quality supplier, and 5\% from high-quality suppliers ( 3 suppliers). The latter 5\% supply appears to contribute in lowering the average TM Plant 1 receives from ordering to low- and medium quality suppliers. On the other hand, about $95 \%$ demand from Plant 2 is fulfilled by low-quality supplier (10 suppliers), followed by $4 \%$ supply from high-quality supplier ( 3 supplier) and $1 \%$ supply from medium-quality supplier. The $95 \%$ order from low-quality supplier ensures that the average percentage of $A$ content meets the specified requirement of Plant 2. Lastly, Plants 3 allocates only about $11 \%$ of order to low-quality supplier ( 1 supplier), about $49 \%$ order to 
medium-quality supplier, and $40 \%$ order to high-quality suppliers ( 2 suppliers). In this allocation scheme, ordering to low- and medium-quality supplier contributes in lowering the total percentage of $A$ content received from high-quality supplier, while ordering to high-quality supplier adjust the average $C V$ and $T M$ into an acceptable value as required by Plant 3.

Table 3. Order Allocation

\begin{tabular}{|c|r|r|r|}
\hline \multirow{2}{*}{ Supplier } & \multicolumn{3}{|c|}{ Order Allocation (ton) } \\
\cline { 2 - 4 } & \multicolumn{1}{|c|}{ Plant 1 } & \multicolumn{1}{|c|}{ Plant 2 } & \multicolumn{1}{c|}{ Plant 3 } \\
\hline 1 & 0 & 9,566 & 434 \\
\hline 2 & 9,969 & 31 & 0 \\
\hline 3 & 5,178 & 822 & 0 \\
\hline 4 & 9,142 & 858 & 0 \\
\hline 5 & 14,142 & 858 & 0 \\
\hline 6 & 0 & 25,000 & 0 \\
\hline 7 & 24,178 & 822 & 0 \\
\hline 8 & 1,251 & 13,749 & 0 \\
\hline 9 & 17,260 & 2,740 & 0 \\
\hline 10 & 9,252 & 748 & 0 \\
\hline 11 & 13,074 & 80 & 1,846 \\
\hline 12 & 22,755 & 245 & 0 \\
\hline 13 & 2,783 & 217 & 0 \\
\hline 14 & 16 & 2,264 & 720 \\
\hline 15 & 0 & 0 & 800 \\
\hline
\end{tabular}

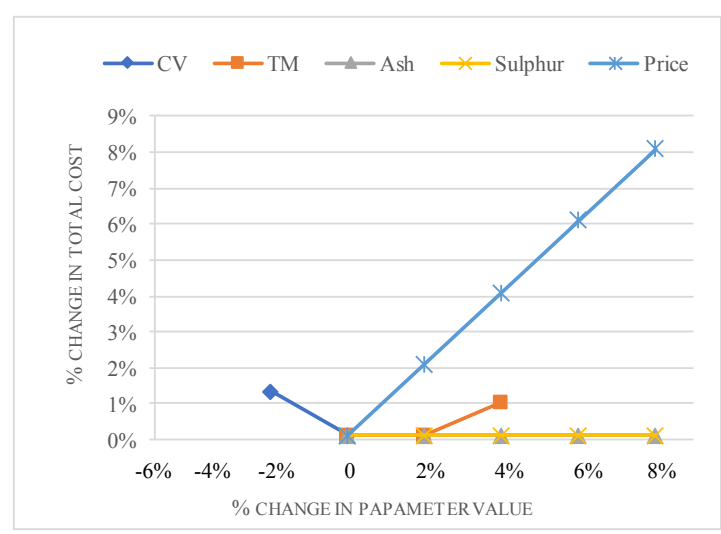

Fig. 1. The Effect of Changing in Parameters on Total Purchasing Cost

Sensitivity analysis is the performed to examine how the change in critical parameters such as quality $(C V, T M, A, S)$ and price affect total cost. To this end, such parameters are varied in the range of $\pm 10 \%$ from the actual values and the result is depicted in Figure 1. It can be seen that the $\mathrm{CV}$ can be reduced to the maximum of $2 \%$ resulting in the increase of total cost by $1.3 \%$. More reduction in CV value causes the total order allocation cannot meet coal demand. On the other hand, \% TM content can be increased to the maximum of $4 \%$ to allow for $100 \%$ fulfilment of coal demand. However, no changes can be observed when $\%$ ash and \% sulphur increase by $8 \%$. Lastly, as expected, the total cost of purchasing proportionately increases as unit purchasing price increased. 


\section{Conclusion}

This study has proposed an LP model to find optimal coal blending quality by using supplier selection and order allocation approach in one of the larget Cement industry named SP. Co. The result shows that with current quality characteristic owned by each supplier, it is still acceptable to involve all of them in supplying coal demand. It is indicated from the solution that all supplier are selected to supply the product to the company. It is also revealed that the CV and TM is critical quality characteristics of coal as small deviation of them may results in demand unsatisfaction. The combination of two parameters changing can be performed in future research to reveal another possible interesting behaviour of quality characteristic to the total cost. Finally, more sophisticated method such as fuzzy multi-linear programming model can also be applied to capture more practical situation.

This research is supported by Faculty of Engineering Andalas University under research grant contract No. 009/UN.16.09.D/PL/2018.

The submission of this article to IMIEC 2018 are supported by the International Conference Aid Program of Andalas University 2018.

\section{References}

1. B. J. Arnold, D. B. Smith, Mining Engineering 14, 2 (1994)

2. Y. Q. Cheng, M. H. Du, W. H. Li, Z. G. Xu, Clean Coal Technology (China) 3, 1 (1997)

3. C. Yin, Z. Luo, J. Zhou, K.Cen, Trans IChemE 78, Part A, (2000)

4. C-M Liua, H. D. Sherali, Omega 28 (2000)

5. G. Xi-jin, C. Ming, W. Jia-wei, Procedia Earth and Planetary Science 1 (2009)

6. A. Chakraborty, M. Chakraborty, Opr. Res. Soc. of India (OPSEARCH) 49, 4 (2012)

7. F. J. Vasko1, D.D. Newhart, A. D. Strauss, J. Oper. Res. Soc. 56 (2005) 